\title{
Stability and osteogenic potential evaluation of micro-patterned titania mesoporous-nanotube
} structures

This article was published in the following Dove Press journal: International Journal of Nanomedicine

\author{
Xi Ding ${ }^{1,2, *}$ \\ Yuzhen Wang ${ }^{1,2, *}$ \\ Lihua $X u^{\prime}$ \\ Hualin Zhang ${ }^{3,4}$ \\ Zhennan Deng ${ }^{2}$ \\ Lina $\mathrm{Cai}^{2}$ \\ Zuosu $\mathrm{Wu}^{2}$ \\ Litao $\mathrm{Yao}^{2}$ \\ Xinghai $\mathrm{Wu}^{2}$ \\ Jinsong $\mathrm{Liu}^{2}$ \\ Xinkun Shen ${ }^{2}$
}

'First Affliated Hospital, Wenzhou Medical University, Wenzhou 325027, People's Republic of China; ${ }^{2}$ School and Hospital of Stomatology, Wenzhou Medical University, Wenzhou 325027, People's Republic of China; ${ }^{3}$ College of Stomatology, Ningxia Medical University, Yinchuan 750004, People's Republic of China; ${ }^{4}$ General Hospital of Ningxia Medical University, Ningxia Medical University, Yinchuan 750004, People's Republic of China

*These authors contributed equally to this work

Correspondence: Hualin Zhang College of Stomatology, Ningxia Medical University, 804\# Shengli South Street,

Xingqing District, Yinchuan, Ningxia Province, People's Republic of China Tel +860 95I 6743450

Email hua3I4I5926@I63.com

Jinsong Liu

School and Hospital of Stomatology, 268\#

Xueyuan West Road, Lucheng District,

Wenzhou City, Zhejiang Province,

People's Republic of China

Tel +8 6057788066085

Email jinsong0719@wmu.edu.cn
Background: Although titanium dioxide nanotubes (TNTs) had great potential to promote osteogenesis, their weak bonding strength with titanium substrates greatly limited their clinical application.

Purpose: The objective of this study was to maintain porosity and improve the stability of TNT coatings by preparing some micro-patterned mesoporous/nanotube (MP/TNT) structures via a photolithography-assisted anodization technology.

Methods: The adhesion strength of different coatings was studied by ultrasonic cleaning machine and scratch tester. The early adhesion, spreading, proliferation and differentiation of MC3T3-E1 cells on different substrates were investigated in vitro by fluorescent staining, CCK8, alkaline phosphatase activity, mineralization and polymerase chain reaction assays, respectively. Results: Results of ultrasonic and scratch assays showed that the stability of TNTs (especially $125 \mathrm{~nm}$ ) was significantly improved after being patterned with MP structures. In vitro cell assays further demonstrated that the insertion of MP structure into $125 \mathrm{~nm}$ TNT coating, which was denoted as MP125, could effectively improve the early adhesion, spreading and proliferation of surface MC3T3-E1 cells without damaging their osteogenic differentiation. Conclusion: We determined that the MP/TNT patterned samples (especially MP125) have excellent stability and osteogenesis properties, and may have better clinical application prospects. Keywords: titanium, micro-patterned structures, coating stability, osteogenic differentiation

\section{Introduction}

As common load-bearing materials, titanium (Ti) and its alloys are widely used for prosthetic applications. ${ }^{1,2}$ However, the biological inertia of Ti materials will contribute to poor osteogenesis, thus inhibiting the osteointegration between implants and natural bone. ${ }^{3}$ For improving their cytocompatibility, various surface modification approaches (especially preparation of functional coatings) have been developed. ${ }^{4-6}$ Some studies had shown that micro/nanostructured or organic coatings could be constructed on the surface of $\mathrm{Ti}$, thus effectively promoting the formation of surrounding new bone. ${ }^{7-11}$ Other researches also reported that the preparation of ceramic coatings (eg, hydroxyapatite, magnesium silicate, calcium phosphate, etc.) on Ti-based implants was an effective way to improve early osteointegration. ${ }^{12-14}$ However, fragments generated by coating peeling may lead to implant loosening or operation failure. ${ }^{15,16}$ Based on the stability considerations, the clinical prospects of these coating-modified materials are greatly inhibited in recent decades. 
Titanium dioxide nanotubes (TNTs) have been widely researched for preparing multifunctional $\mathrm{Ti}$ implants due to their regular tubular nanostructures, size controllability and drug-loading properties. ${ }^{17,18}$ Although TNT materials have shown remarkable osteogenic effects in vitro and in vivo (in rats or rabbits), their weak bonding strength with Ti substrate greatly limits their clinical application. ${ }^{19-22}$ For improving the stability of TNT coatings, some explorations have been attempted. For example, Xiong et al proved that annealed TNTs $\left(500^{\circ} \mathrm{C}, 10 \mathrm{hrs}\right)$ had better coating adhesion quality than untreated samples. ${ }^{23} \mathrm{Li}$ et al constructed a compact oxide layer (about $200 \mathrm{~nm}$ thick) between TNTs and substrate through an additional anodization and demonstrated that the critical load of treated TNTs increased three times. ${ }^{22}$ Zhu et al further improved the critical load (about 5.8 times) of TNTs coatings with double additional compact layers. ${ }^{24}$

In this work, we expected to construct micro-patterned mesoporous (MP) regions by photolithography-assisted anodization technique to improve the stability of TNT coatings. Photolithography has been widely used to create surface topographies with the assistant of photoresist, patterned mask and ultraviolet (UV, $365 \mathrm{~nm}$ ) light. ${ }^{25-27}$ Since MP structure has the advantages of large surface area, high crystallinity, good mechanical stability and flexibility, the corresponding transition region may help to offset some internal stress, thus ensuring the stability of TNT coatings. ${ }^{28,29}$ Moreover, previous studies also claimed that surface micro/nanohierarchical structures had a stronger ability to promote new bone formation than the micro or nanostructures alone. ${ }^{30-32}$ Hence, we believe that the micro-patterned structures might have great potential to promote osteogenesis while improving the TNTs stability.

Three issues would be addressed as follows in this study: (1) to prepare MP/TNT-patterned specimens through the combined techniques of photolithography and anodization; (2) to investigate the coating stability of different samples; and (3) to evaluate the biological properties (eg, protein adsorption, cell proliferation, osteogenic differentiation, etc.) of different substrates in vitro.

\section{Materials and methods Materials}

Ti sheets (purity: 99.6\%; thickness: $1 \mathrm{~mm}$ ) were purchased from Advent Research Materials Ltd. (Oxford, UK). Photolithography materials were provided by Futurrex Inc. (NJ, USA). Photolithography chrome mask was made in Qingwei Co. (Jiangsu, China). Bicinchoninic acid (BCA) and p-nitrophenyl phosphate assay kits were obtained from Beyotime Biotechnology Co. (Jiangsu, China). Fluorescein isothiocyanate-bull serum albumin (FITC-BSA), PhalloidineX, 3-(4,5dimethylthiazol-2yl)-2, MTT, Hoechst 33,258 and all other chemicals used in this study were provided by Sigma-Aldrich Co. (MO, USA).

\section{Specimen preparation and characterization}

Ti sheets were first polished with silicon carbide sandpapers (800, 1,000 and 1,200 grits), cleaned thoroughly by sequential sonication in acetone, isopropyl alcohol and deionized water, and then dried with nitrogen stream. The preparation illustrations of MP, TNTs (TNT15 \& TNT125) and MP/TNT-patterned specimens (MP15 \& MP125) are displayed in Scheme 1. Briefly, for preparation of MP specimens, the corresponding electrolyte (anhydrous glycerol containing $10 \mathrm{wt} \%$ $\mathrm{K}_{2} \mathrm{HPO}_{4}$ ) was held at $200^{\circ} \mathrm{C}$ for $4 \mathrm{hrs}$ to reduce the excessive water. Next, cleaned Ti were anodized in the above electrolyte at $20 \mathrm{~V}$ for $1 \mathrm{hr}$ and $50 \mathrm{~V}$ for 20 mins in a two-electrode system at $180^{\circ} \mathrm{C}$ and finally treated in $30 \mathrm{wt} \% \mathrm{H}_{2} \mathrm{O}_{2}$ solution under ultrasonic condition for $1 \mathrm{hr}$. Unlike MP preparation, the anodization of TNT15 and TNT125 samples was carried out at 6 and $40 \mathrm{~V}$ for $2 \mathrm{hrs}$ (at ambient temperature) in the electrolyte of $\mathrm{H}_{2} \mathrm{O} /$ glycerol mixture solution containing $0.27 \mathrm{M}$ ammonium fluoride, respectively. In order to further prepare composite MP15 and MP125, the MP specimens were first coated with photoresist, exposed to UV light ( $365 \mathrm{~nm}$ ) through masker aligner (square light-transmitting area with side length of $200 \mathrm{~nm}$ and interval of $240 \mathrm{~nm}$ ), and then soaked in alkaline solution to remove the irradiated regions. After that, these patterned MP specimens were further anodized according to the preparation process of TNTs. All treated samples were rinsed with deionized water and dried with nitrogen stream.

Surface morphology of different substrates (Ti, MP, TNT15, TNT125, MP15 and MP125) was characterized by scanning electron microscopy (SEM; JSM-6700F, JEOL, Tokyo, Japan). The wettability of different samples was assessed by sessile drop method using a contact angle apparatus with a horizontal microscope (Model 200, Future Scientific, Taiwan, China).

\section{Coating stability}

For investigating the stability of different coatings, MP, TNT15, TNT125, MP15 and MP125 specimens were soaked into deionized water and then ultrasonically treated at $300 \mathrm{~W}$ for $4 \mathrm{hrs}$ using an ultrasonic cleaning machine 


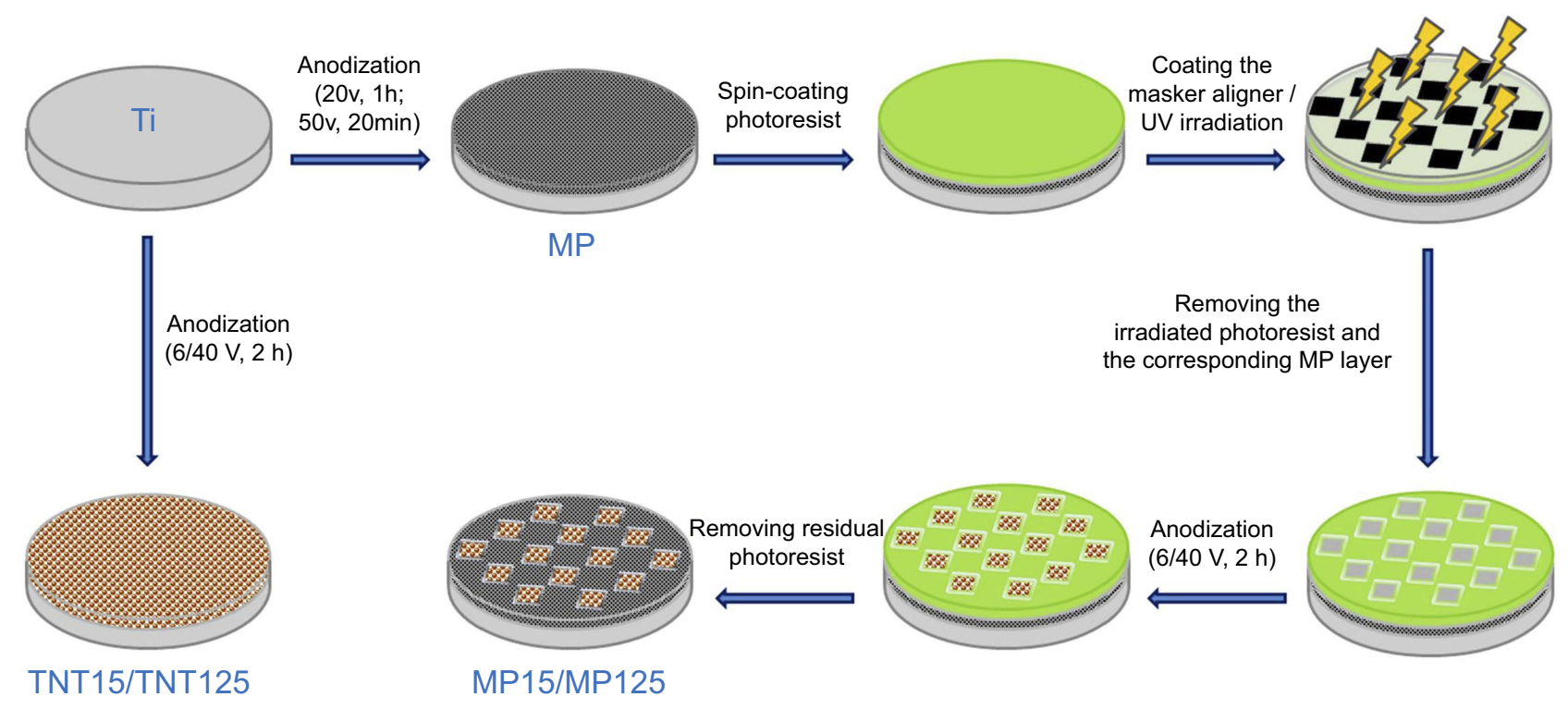

Scheme I Schematic illustration of the preparation of different titanium-based substrates.

(SB-5200DT, Ningbo, China). The soaking water was collected for detecting the content of $\mathrm{TiO}_{2}$ fragments dropped from different samples using an UV/Vis/NIR spectrometer (Lambda 900, PerkinElmer instruments, USA). The representative TNT125 fragments in soaking water were also characterized by SEM. Meanwhile, after cleaning three times with deionized water and drying with nitrogen stream, surface morphology of different samples was observed through the stereomicroscope (SMZ800N, Tokyo, Japan) and SEM. Next, the coating stability was further investigated via the scratch test using a scratch tester (CSM Instruments, Switzerland). The progressive load was from 1 to $20 \mathrm{~N}$. The initial stripping force of the coating around scratch tracks was analyzed in this work.

\section{Protein adsorption}

FITC-BSA was firstly dissolved in PBS solution. Then, different samples were separately soaked in $0.5 \mathrm{~mL}$ of FITC-BSA $(1 \mathrm{mg} / \mathrm{mL})$ solution at $37^{\circ} \mathrm{C}$ at different time points (10, 30 and $120 \mathrm{mins})$. A $0.1 \mathrm{~mL}$ of soaking solution was collected to measure the fluorescence intensity of residual FITC-BSA at the excitation wavelength of $488 \mathrm{~nm}$. The adsorption value of FITC-BSA by different substrates was calculated by the standard curve. Meanwhile, after soaking for 120 mins, all samples were collected and washed three times with PBS for fluorescence visualization using an inverted fluorescence microscope (FM, OLYMPUS IX71, Japan).

\section{Cell culture}

MC3T3-E1 cells were obtained from ATCC (Manassas, VA, USA) and cultured with $\alpha$-MEM medium supplemented with $10 \%$ fetal bovine serum under $5 \% \mathrm{CO}_{2}$ atmosphere at $37{ }^{\circ} \mathrm{C}$. The cell culture medium was refreshed every 3 days. Cells at the initial density of $1 \times 10^{4}$ cells $/ \mathrm{cm}^{2}$ were seeded onto various samples in this study.

\section{Cell adhesion}

MC3T3-E1 cells were seeded onto different substrates for 1,3 and $5 \mathrm{~h}$. After fixing cells with $4 \%$ glutaraldehyde for 30 mins at $4{ }^{\circ} \mathrm{C}, 0.2 \%$ Triton-X100 solution was used to penetrate cell membranes for 10 mins. Then, all adherent MC3T3-E1 cells were stained with rhodamine-phalloidin $\left(4^{\circ} \mathrm{C}\right.$, overnight $)$ and $\mathrm{H} 33258$ solution (ambient temperature, 15 mins), and finally observed using an inverted fluorescence microscope (FM, OLYMPUS IX71, Japan).

\section{Cell viability}

MTT assay was used to evaluate the cell proliferation in this work. After culturing MC3T3-E1 cells for 1, 5, 10 and $15 \mathrm{~d}$, $200 \mu \mathrm{L}$ mixture solution of medium and MTT $(5 \mathrm{mg} / \mathrm{mL})$ (v: $v=9: 1$ ) was added to each well and incubated at $37^{\circ} \mathrm{C}$ for another $4 \mathrm{hrs}$. A $0.3 \mathrm{~mL}$ of dimethyl sulfoxide was then added to dissolve the formed formazan crystals. The absorbance was measured at a wavelength of $490 \mathrm{~nm}$ with a microplate reader (Bio-Rad 680, USA). 


\section{Alkaline phosphatase (ALP) activity}

After culturing for $10 \mathrm{~d}$, the adherent MC3T3-E1 cells were lysed by $1 \%$ Triton-X100 solution $(200 \mu \mathrm{L})$ at $4{ }^{\circ} \mathrm{C}$ for 30 mins. The ALP activity in cell lysate was determined using a p-nitrophenyl phosphate kit according to its manufacturer instruction. Meanwhile, the total protein content in the lysate was also measured with a BCA kit for normalizing ALP activity. The absorbance for ALP and BCA detection was 490 and $570 \mathrm{~nm}$, respectively.

\section{Mineralization}

After culturing for $10 \mathrm{~d}$, MC3T3-E1 cells on different substrates were fixed with $4 \%$ glutaraldehyde and stained with alizarin red solution ( $\mathrm{pH} 4.1)$, respectively. Cells were then treated by acetic acid $(10 \% \mathrm{v} / \mathrm{v})$ and ammonium hydroxide $(10 \% \mathrm{v} / \mathrm{v})$ and quantitatively measured at $405 \mathrm{~nm}$ with a spectrophotometric microplate reader.

\section{Gene expression}

After culturing MC3T3-E1 cells for 3 and $10 \mathrm{~d}$, the expression of ALP, collagen I (COL I), osteopontin $(\mathrm{OPN})$ and osteocalcin $(\mathrm{OCN})$ genes were determined by real-time PCR analysis and normalized by GAPDH gene. All related primers are displayed in Table 1. The cDNA obtained by reverse transcription was amplified using a Bio-Rad CFX Manager system under $95^{\circ} \mathrm{C}$ for 3 mins, following by 40 cycles of $95^{\circ} \mathrm{C}$ for $5 \mathrm{~s}$ and $60^{\circ} \mathrm{C}$ for $30 \mathrm{~s}$.

\section{Statistical analysis}

All data were expressed as means $\pm \mathrm{SD}$. The statistical analysis was performed with OriginPro (version 7.5) via

Table I Real-time polymerase chain reaction primers used in this study

\begin{tabular}{|l|l|}
\hline Target genes & Primers \\
\hline ALP & F: 5'- GAACAGAACTGATGTGGAATACGAA - 3' \\
OPN & R:5'- CAGTGCGGTTCCAGACATAGTG - 3' \\
OCN & F: 5'- GATGTTGAACTTGTTGTTGCTGAGGG - 3' \\
& R: 5'- GGCAGGCGAGATGGCTTATT - 3' \\
& F: 5'- GTGATTTGCTTTTGCCTGTTTG - 3' \\
& R: 5'- GGAGATTCTGCTTCTGAGATGGG - 3' \\
& F: 5'- GAACAGACAAGTCCCACACAGC - 3' \\
& R: 5'- TCAGCAGAGTGAGCAGAAAGAT- 3' \\
\hline GAPDH & F:5'- CTCGTCCCGTAGACAAAATGGT - 3' \\
& R:5'- GAGGTCAATGAAGGGGTCGTT - 3' \\
\hline
\end{tabular}

Student's $t$-test and one-way ANOVA. The confidence levels were set as $95 \%$.

\section{Results and discussion Characterization of different samples}

SEM images (Figure 1A) displayed that there was no significant difference in the macroscopic morphology of Ti, MP, TNT15 and TNT125. However, different from the smooth surfaces of Ti, some scattered MP and regular TNT structures were observed in the high-resolution images of MP, TNT15 and TNT125. Further statistics (Figure 1C) showed that the pore sizes of MP, TNT15 and TNT125 were around 10.3 $\pm 4.0,15.8 \pm 3.9$ and $125.9 \pm 10.6 \mathrm{~nm}$, which were consistent with our previous studies. ${ }^{20,29}$ Compared to the above samples (Ti, MP, TNT15 and TNT125), a regular square recessed area (side length: $\sim 200 \mu \mathrm{m}$; depth: $\sim 2 \mu \mathrm{m}$ ) appeared on the surfaces of MP15 and MP125 (Figure 1A and B). Since the sample was acid etched before preparing nanotube samples, there were some obvious micro-pits (about 10-20 $\mu \mathrm{m}$ ) with different nanotubes (15 or $125 \mathrm{~nm}$ ) in the above-recessed area. Similar hybrid structures had been observed in the previous study. ${ }^{33}$ It was also discovered that the MP structures (around $10 \mathrm{~nm}$ ) of photoresist-covered area in MP15 and MP125 were intact (Figure 1A and C). Moreover, the cross-sectional images of TNT125 further showed that the coating thicknesses of MP and TNT were about 1.9 and 2.1 $\mu \mathrm{m}$, respectively (Figure 1B). The phenomenon that the depth of square recessed area $(\sim 2 \mu \mathrm{m})$ was slightly larger than MP depth $(\sim 1.9 \mu \mathrm{m})$ might be caused by the loss of titanium dioxide during acid etching and TNT preparation.

Next, results of water contact angle (Figure 2) displayed that Ti surface $\left(\sim 78.3 \pm 2.3^{\circ}\right)$ had the most hydrophobic property among all samples. On the contrary, TNT125 exhibited super-hydrophilic properties $(\sim 5.0$ $\left.\pm 1.6^{\circ}\right)$, which was consistent with previous studies. ${ }^{17} \mathrm{MP}$ and TNT15 had moderate wettability and were around $57.9 \pm 6.0^{\circ}$ and $38.1 \pm 7.9^{\circ}$. Moreover, it was found that the water contact angle of MP15 and MP125 changed to 32.2 $\pm 5.2^{\circ}$ and $17.3 \pm 2.1^{\circ}$, respectively. In general, the contact angle of a material might be inversely related to its surface energy. ${ }^{34,35}$ Accordingly, we conclude that five modified materials (especially TNT125 and MP125) had higher surface energies than native Ti.

\section{Coating stability}

To investigate the stability of NT and NP layers, ultrasonic and scratch treatments were carried out in this work. From 


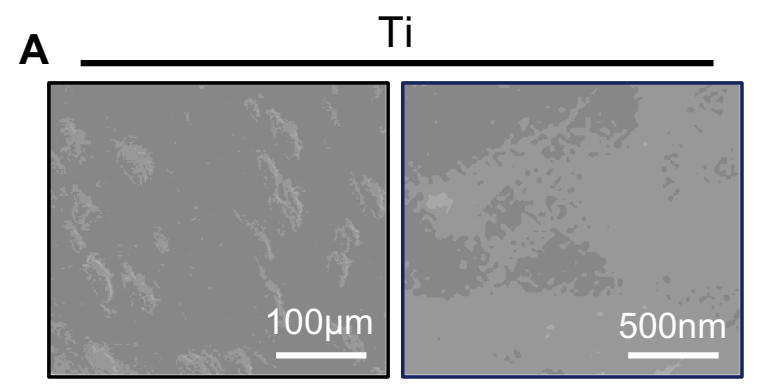

TNT15

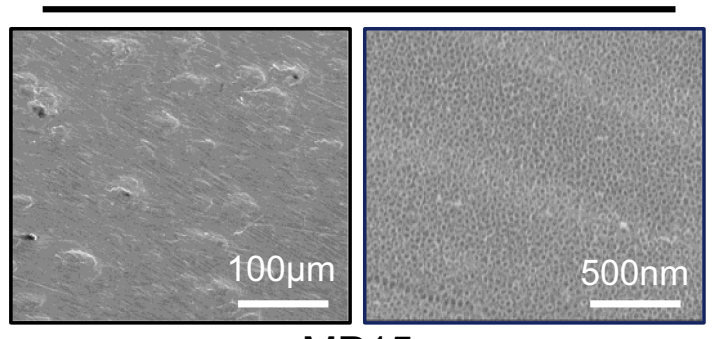

MP15

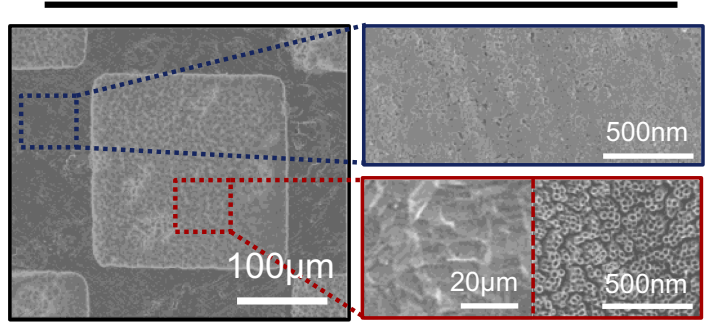

B
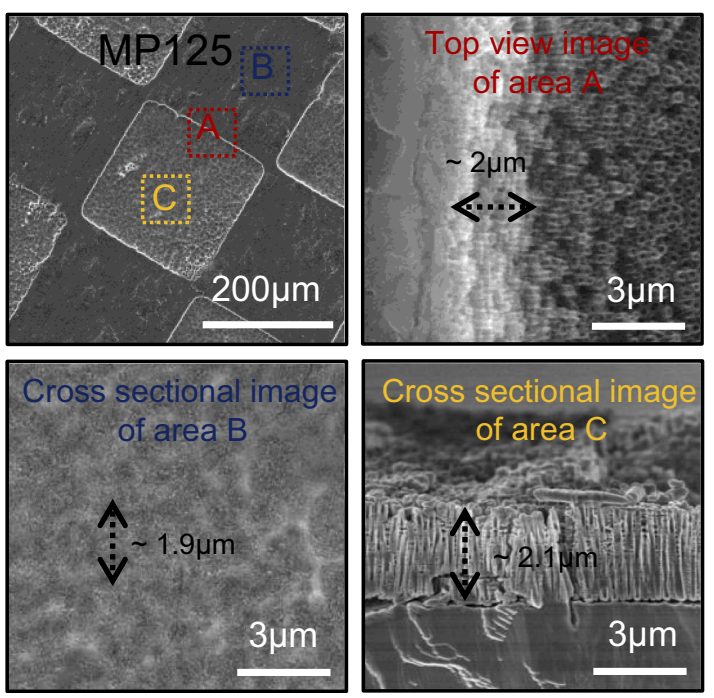

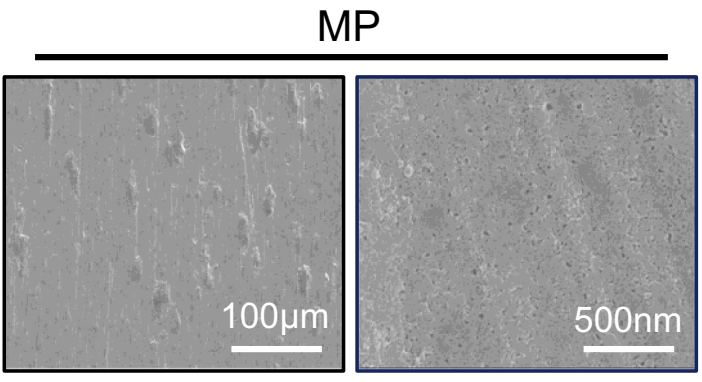

TNT125

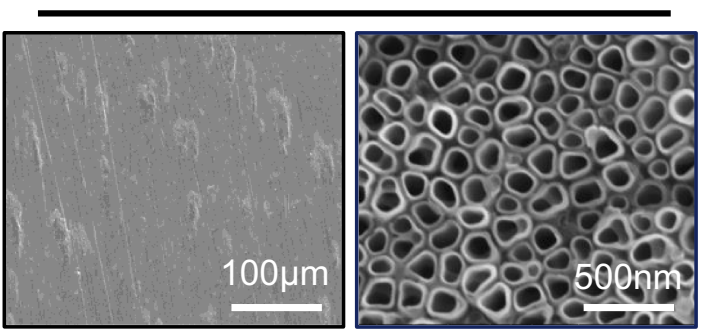

MP125

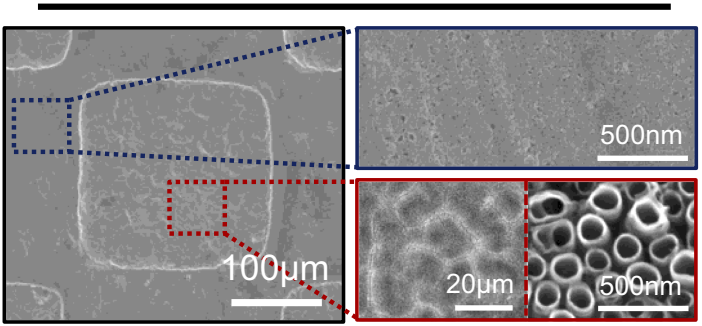

C

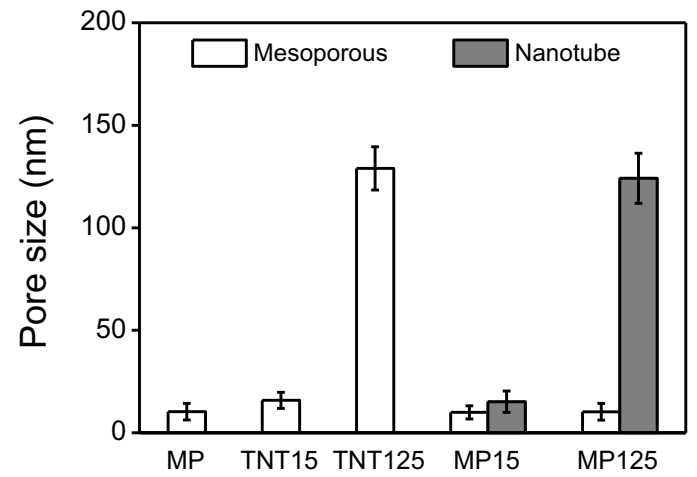

Figure I (A) Scanning electron microscopy images of different substrates (left: low magnification; right: high magnification); (B) top view and cross-section images of MPI25 in different area; $(\mathbf{C})$ pore size statistics of mesoporous and nanotube.

Figure 3A, it was found that only TNT125 had obvious coating peeling after $4 \mathrm{hrs}$ of ultrasound, while coatings of other groups were complete. Many micro/nano-scale fragments were observed in the soaking solution of TNT125 specimens (Figure 3B). The result of UV absorption spectrum showed that $\mathrm{TiO}_{2}$ had an absorption band in the range of $250-380 \mathrm{~nm}$, and the maximum absorption peak was around $330 \mathrm{~nm}$ (Figure 3B). It was consistent with the previous study. ${ }^{36}$ We also discovered that the absorption value trend of various soaking solutions at $330 \mathrm{~nm}$ was as follows: TNT125> TNT15> MP125/MP15/MP. Moreover, through the scratch result (Figure 3C), we further verified 


\section{A}
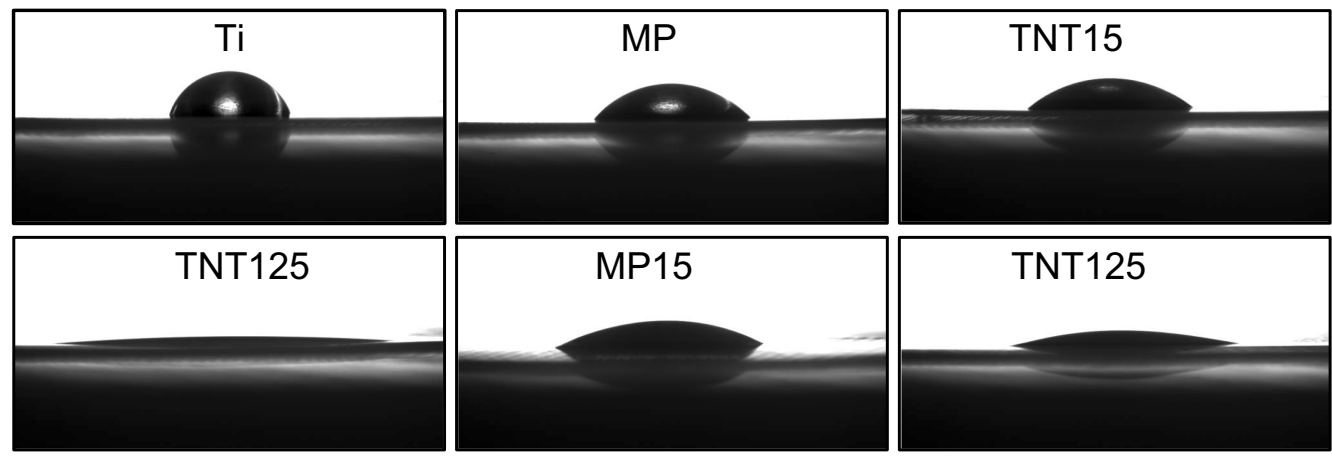

B

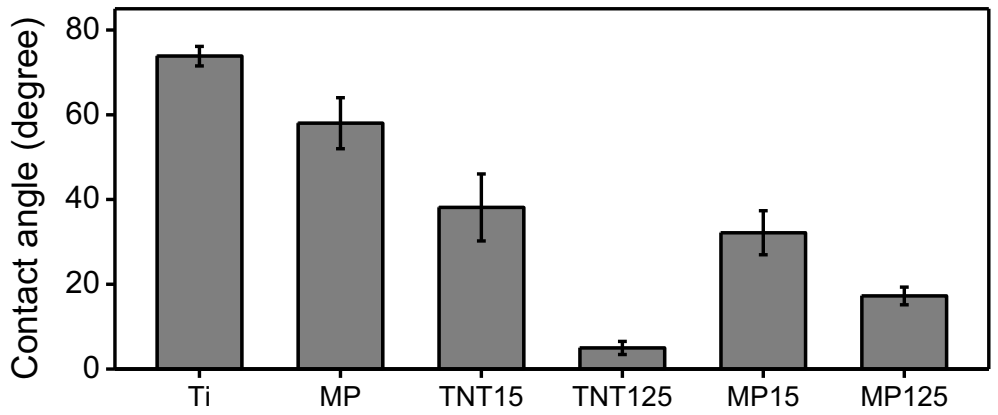

Figure 2 (A) Representative images of water contact angles; (B) statistics of water contact angle of different substrates.

that TNT125 has the weakest coating stability and its stripping force was less than $1 \mathrm{~N}$. The initial stripping force of TNT15 was also small and about $4 \mathrm{~N}$. But no obvious peeling phenomenon was observed within the rage of 20 N in MP, MP15 and MP125 groups. The stability improvement of TNTs in patterned samples (MP15 and MP 125) might be attributed to the fact that the transition region of MP could greatly relieve the stress on the TNT coating. ${ }^{37}$ Above results indicate that the stability of TNTs (both 15 and $125 \mathrm{~nm}$ ) could be greatly improved by patterning treatment with MP structures.

\section{Protein adsorption}

Studies had shown that when the materials were implanted into the body, some surrounding proteins would quickly adhere to their surfaces, and the formed protein layer was proved to have a significant impact on subsequent cell behaviors (eg, survival, proliferation, differentiation, etc.). ${ }^{38-40}$ From Figure 4A, it was found that five modified specimens (MP, TNT15, TNT125, MP15 and MP125) could adsorb more FITC-BSA proteins $(p<0.05)$ than native $\mathrm{Ti}$ at 30 and 120 mins (further proved by Figure 4B). However, only TNT125 group had the highest FITC-BSA adsorption after incubation for 10 mins. It suggests that large TNTs were more conducive to protein adsorption than the small TNTs and native $\mathrm{Ti}$ in the early stage. Yang et al had proved that more collagen and fibronectin could be adsorbed by the TNTs with bigger dimensions, which was attributed to their higher interaction energies. ${ }^{41}$ Thus, the excellent protein adsorption performance of TNT125 in this paper was also most likely due to their higher surface energies (confirmed by the contact angle results in Figure 2). Moreover, compared to TNTs alone, the micro-patterned structures did not present significant effects on protein adsorption.

\section{Cell adhesion, morphology and viability}

The adhesion and morphology of MC3T3-E1 cells on different substrates within $5 \mathrm{hrs}$ were observed in this study. From he Figure 5A, it was found that there was no significant difference in the number of cell adhesion on different samples at $1 \mathrm{hr}$, and all cells showed spherical shape. After culturing for $3 \mathrm{hrs,} \mathrm{more}$ cells were adhered to the surface of MP, TNT15 and MP15 samples (further confirmed by Figure 5B) than those of other groups $(p<0.05)$. It was also observed that most MC3T3-E1 cells on TNT125 did not unfold significantly, but spread well on other samples. As the culture time was extended to $5 \mathrm{hrs}$, the 
A
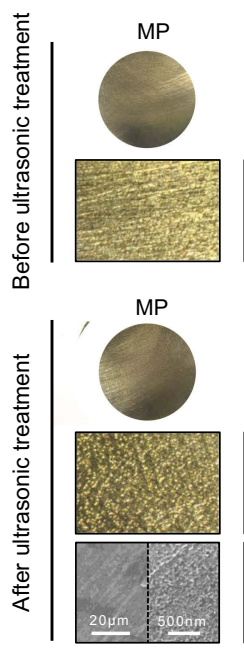
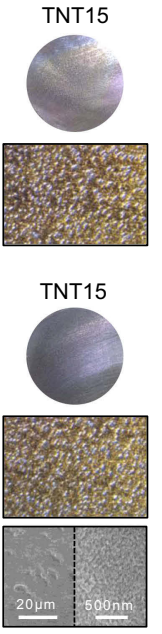

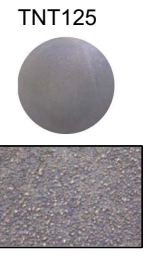

TNT125
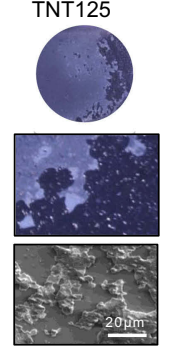
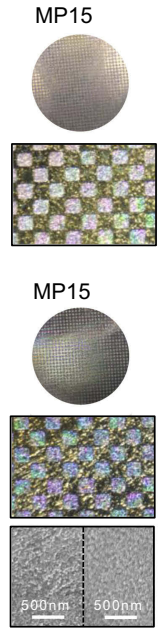

B

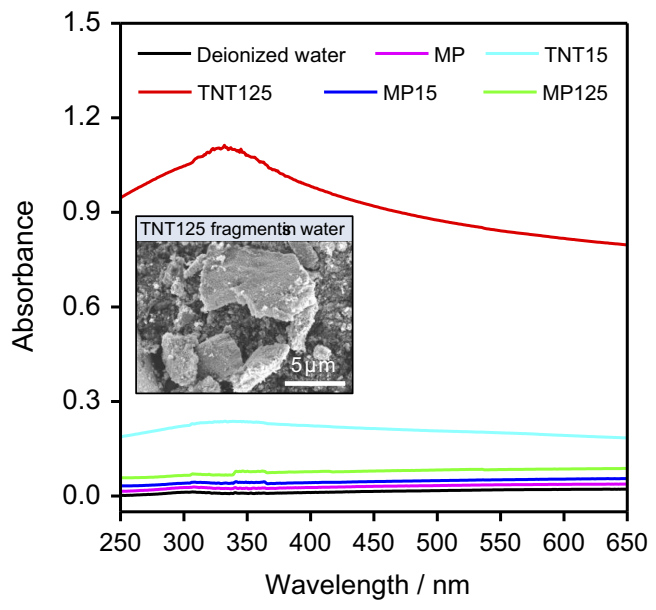

C

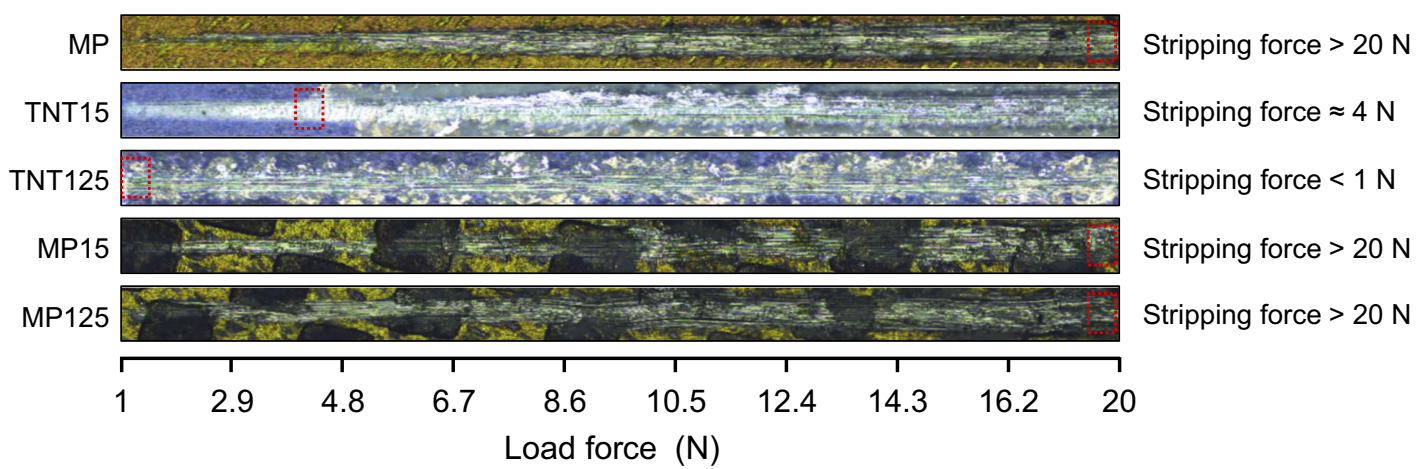

Figure 3 (A) Optical and scanning electron microscopy images of different substrates before and after ultrasonic treatment; (B) UV absorption spectrum of TiO ${ }_{2}$ fragments in different soaking solutions and the representative SEM image of TNTI 25 fragments in soaking water; (C) representative scratch track image of different samples (I-20 N).

number of cells in all groups further increased. Combined with the statistical data of Figure $5 \mathrm{~B}$ and $\mathrm{C}$, we determined that the TNT15 and MP groups showed the highest cell number and largest spreading area compared with other groups, respectively $(p<0.05)$. It was caused by that more integrin (ITG) would be expressed by osteoblasts on the surface of small TNTs $(15 \mathrm{~nm}){ }^{17,42}$ Yu et al had reported that compared with large TNTs, small TNTs could greatly increase the expression of some ITG genes (ITG $\alpha 1$, ITG $\alpha 3$ and ITG $\beta 1$ ) and the early adhesion of osteoblasts. ${ }^{17}$ Iglič et al also demonstrated that small TNTs had more sharp convex edges and ITG-binding regions per unit area than large TNTs, thus effectively binding the extracellular part of the ITG molecules and further improve early adhesion and spreading of osteoblasts. ${ }^{42}$ Moreover, MC3T3-E1 cells on TNT125 still exhibited the worst adhesion and spreading at $5 \mathrm{hrs}$ since large TNTs had fewer cell adhesion sites. ${ }^{42,43}$ The poor adhesion/spreading properties of TNT125 were effectively improved by the MP structures in MP125 group.
Next, cell viability of MC3T3-E1 cells at 1, 5, 10 and $15 \mathrm{~d}$ was measured and the corresponding result was displayed in Figure 6A. No significant difference was found among all groups at $1 \mathrm{~d}$. However, the cells on TNT15 had the highest viability after 5 and $10 \mathrm{~d}$ of culture $(p<0.05)$. Compared to other groups, TNT125 samples presented the worst effects in promoting cell proliferation at 5,10 and $15 \mathrm{~d}$. It was consistent with the previous study that reported that large TNTs were beneficial to osteogenic differentiation but not conducive to cell proliferation. ${ }^{21}$ In addition, similar to adhesion results, the cell viability of MP125 group was higher than that of TNT125 group at 10 and $15 \mathrm{~d}(p<0.05)$. Above results collectively indicate that MP-mediated patterning structures (MP125) had great potential to improve the early adhesion, spreading and viability of MC3T3-E1 cells on TNT125.

\section{ALP activity and mineralization}

The activity of ALP, an external enzyme of osteoblasts, was usually used as an indicator to evaluate the early osteogenic 
A

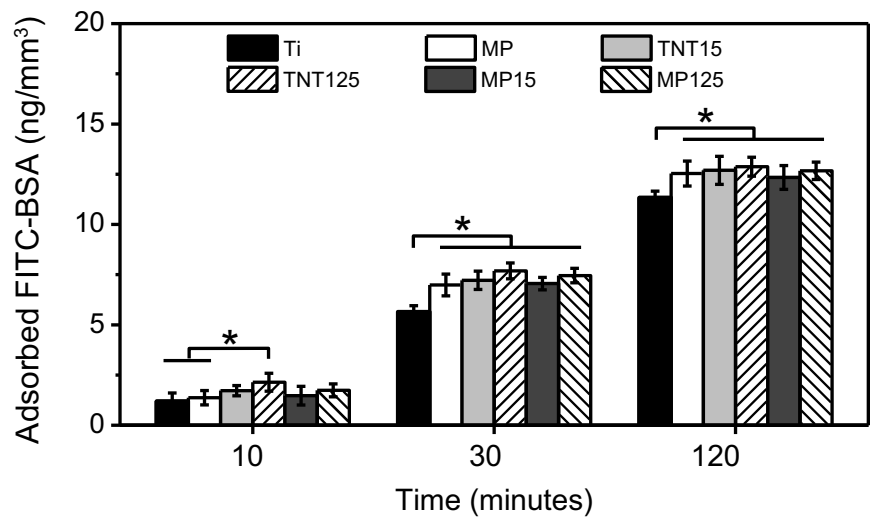

B
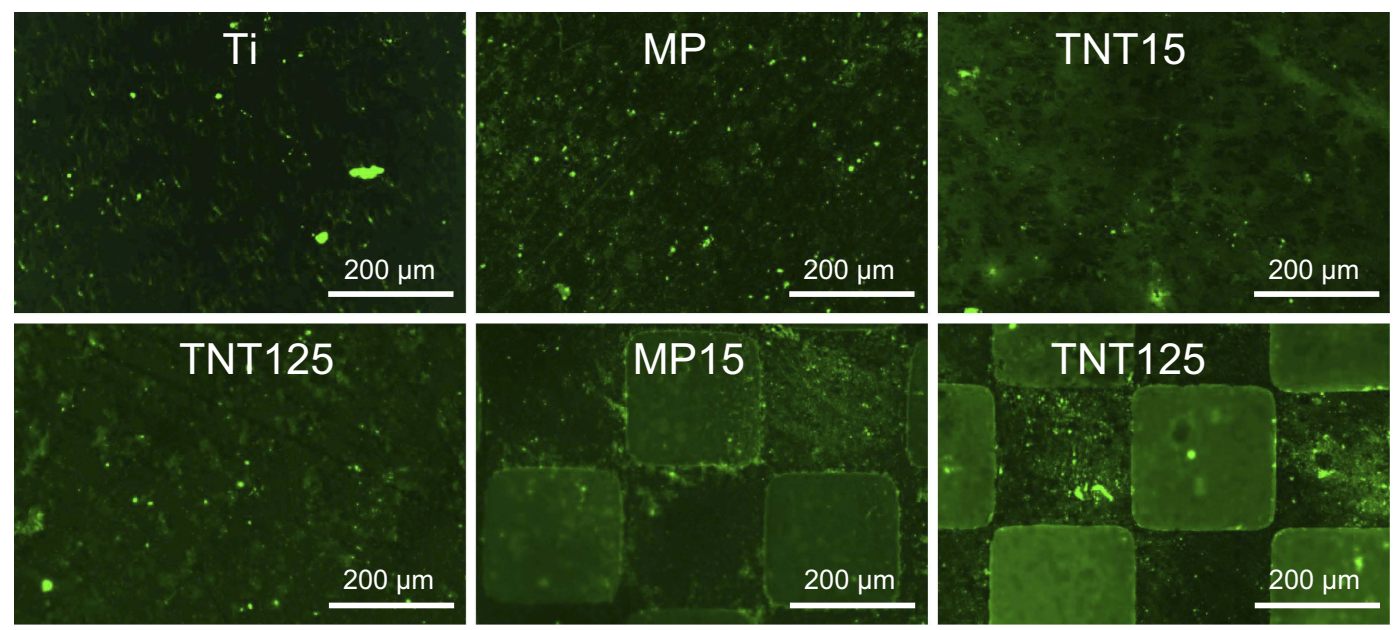

Figure 4 (A) Statistics of adsorbed FITC-BSA protein on different samples at 10, 30 and I20 mins; (B) representative fluorescent images of adsorbed FITC-BSA protein at 120 mins. Error bars represent mean \pm SD for $n=6,{ }^{*} p<0.05$.

differentiation of osteoblasts. ${ }^{44,45}$ From Figure 6B, it was found that MC3T3-E1 cells on TNT125 surface had the higher ALP activity than those of Ti and MP groups at $10 \mathrm{~d}$ $(p<0.05)$. Compared to Ti group, TNT15, MP15 and MP125 samples were also proved to significantly increase ALP activity $(p<0.05)$. However, no significant difference was detected among TNT15, TNT125, MP15 and MP125 groups. Meanwhile, a trend similar to ALP activity was also observed in the mineralization result (Figure 6C). The results of ALP activity and mineralization level suggest that both TNT and MP/TNT patterned structures could greatly promote the osteoblastic differentiation of MC3T3E1 cells.

\section{Osteogenic gene expression}

In order to further evaluate the osteogenic potential of different specimens, the expression of some related genes (ALP, COL I, OPN and OCN) was measured at the molecular level. ${ }^{46}$ The corresponding results are shown in Figure 7. After culturing for $3 \mathrm{~d}$, the expression of ALP and COL I genes in MC3T3-E1 cells on five modified samples (MP, TNT15, TNT125, MP15 and MP125) was significantly $(p<0.05)$ increased when compared with that of $\mathrm{Ti}$ (Figure 7A). It was also found that TNT125 and MP125 had the greatest ability to increase the expression of ALP, COL I, OPN and OCN genes in all groups. Moreover, similar to the result of $3 \mathrm{~d}$, both TNT125 and MP125 also significantly $(p<0.05)$ promoted the expression of four genes in surface MC3T3-E1 cells compared with Ti at 10 d (Figure 7B).

Above results (Figures $6 \mathrm{~B}$ and 7 ) displayed that MC3T3-E1 cells on TNT125 and MP125 samples had the higher ALP activity and osteogenic genes expression at 3 and/or $10 \mathrm{~d}$ than those of other groups. The previous study had proved that the absence of ALP would not affect the expression of COL I, OPN and OCN genes, but would significantly hinder the mineralization process of 


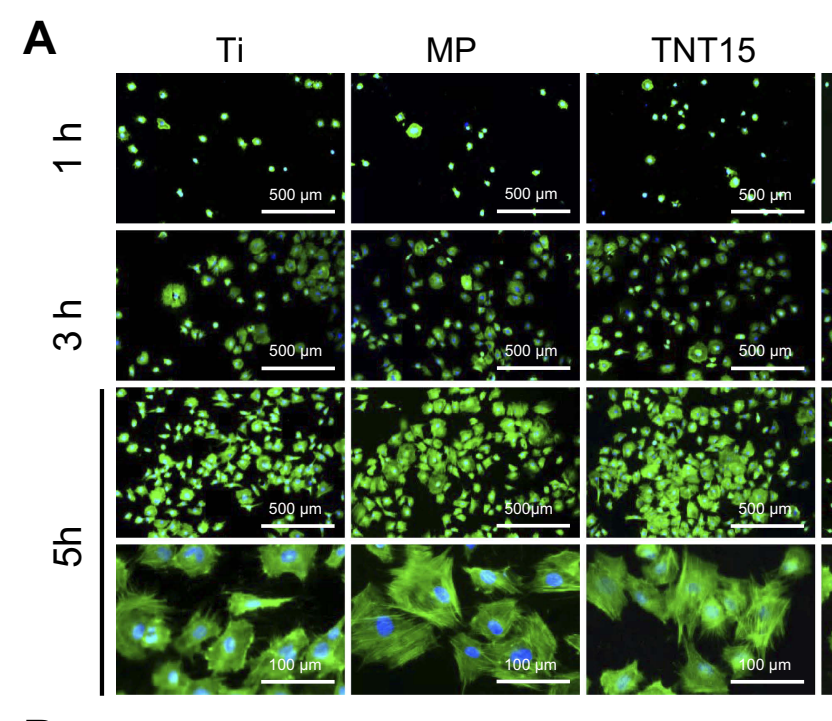

B

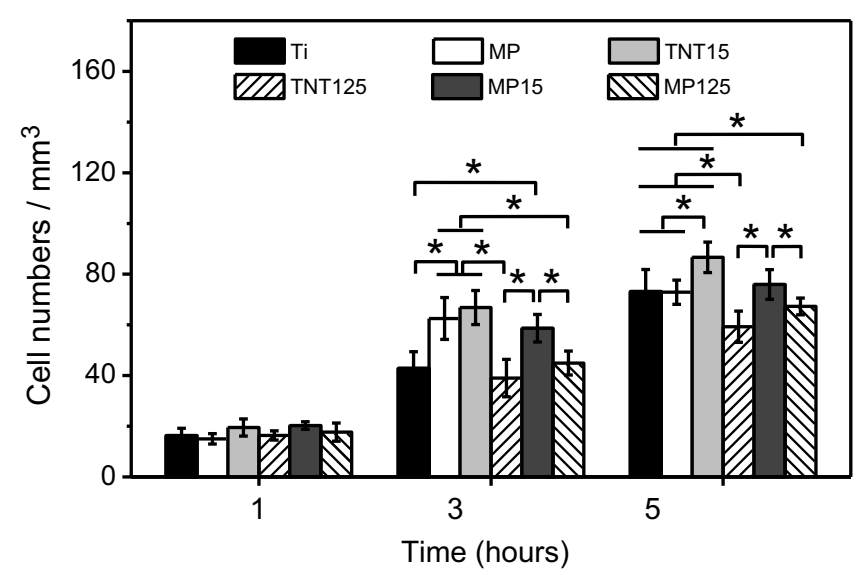

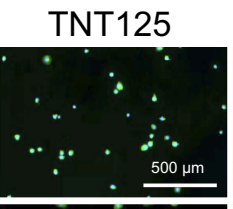

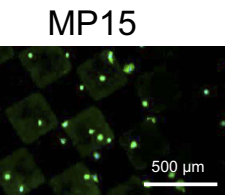

MP125
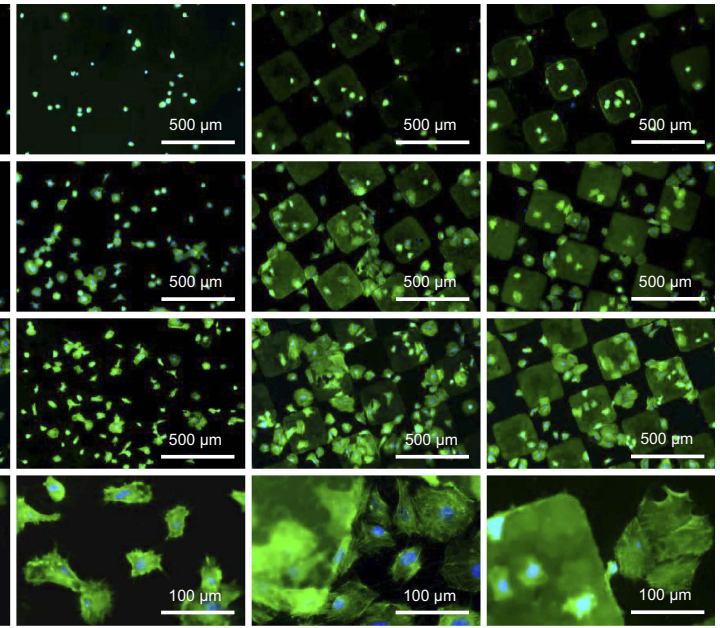

C

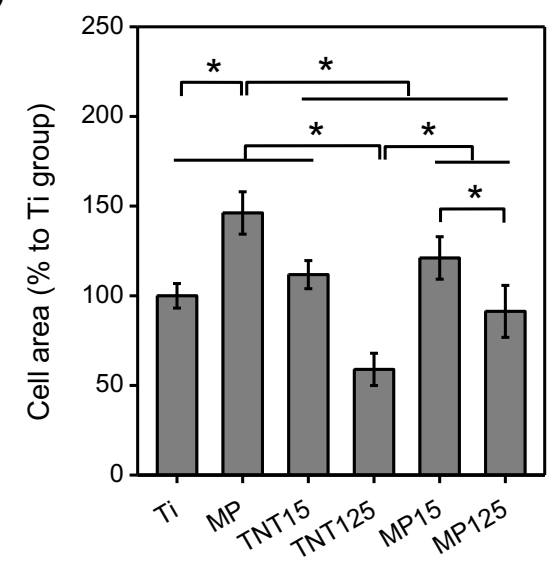

Figure 5 (A) Representative fluorescent images of adherent MC3T3-EI cells at I, 3 and 5 hrs; statistics of cell numbers (B) and spreading area (C) (at 5 hrs) according to fluorescent images. Error bars represent mean \pm SD for $n=6,{ }^{*} p<0.05$.

osteoblasts. ${ }^{47}$ Since ALP had the ability to hydrolyze phosphate ester and pyrophosphate, it could provide sufficient phosphate for bio-mineralization and accelerate the formation of new bone. ${ }^{48}$ Thus, the higher ALP activity and osteogenic genes expression in TNT125 and MP125 groups would greatly increase the mineralization level, which was confirmed by the mineralization result (Figure 6C). Results of ALP activity, mineralization level and osteogenic gene expression collectively indicate that TNT125 and MP125 had great potential to promote the osteoblastic differentiation of osteoblasts.

\section{Conclusion}

Micro-patterned structures of mesoporous (pore size about $10 \mathrm{~nm}$ ) and nanotube (pore size about 15 or 125 $\mathrm{nm}$ ) were successfully constructed on Ti surface through the combined techniques of photolithography and anodization in this study. It was proved that micropatterned specimens (MP15 and MP125) had higher coating stability than the nanotubes alone (TNT15 and TNT125). Meanwhile, compared to TNT125 group, MP125 not only maintained the excellent osteogenic differentiation potential of MC3T3-E1 cells, but also significantly promoted the cell adhesion, spreading and proliferation. This study provides a new way to improve the stability and biocompatibility of nanotube coatings at the same time, and the porous structures (nanotube and mesoporous) of micro-patterned samples may be further used as carriers to prepare drug-device composite titanium implants in the future.

\section{Acknowledgments}

This work was financially supported by National Natural Science Foundation of China (81870810 and 31700827), 
A

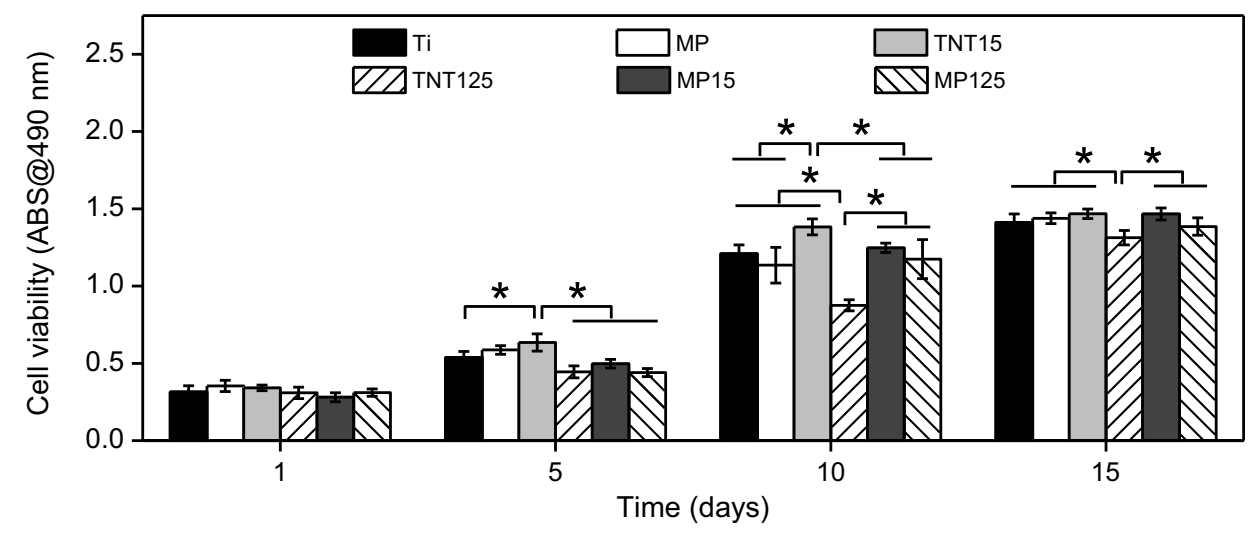

B

C
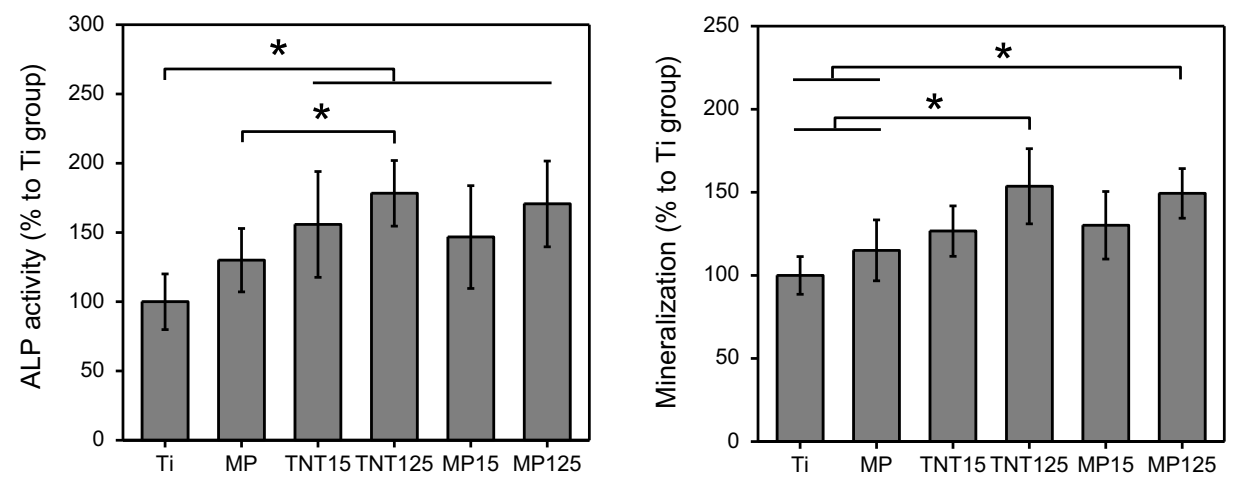

Figure 6 (A) Cell viability of MC3T3-EI cells at I, 5, 10 and I 5 d; statistics of ALP activity (B) and mineralization level (C) at $10 \mathrm{~d}$. Error bars represent mean \pm SD for $n=6, * p<0.05$.

A

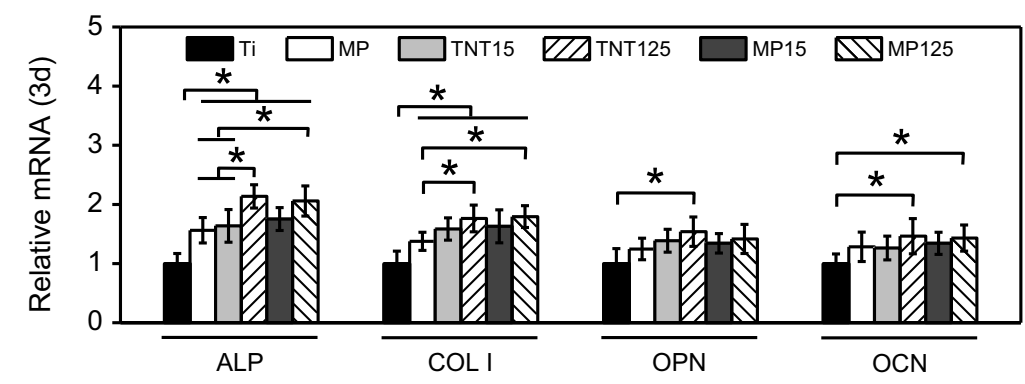

B

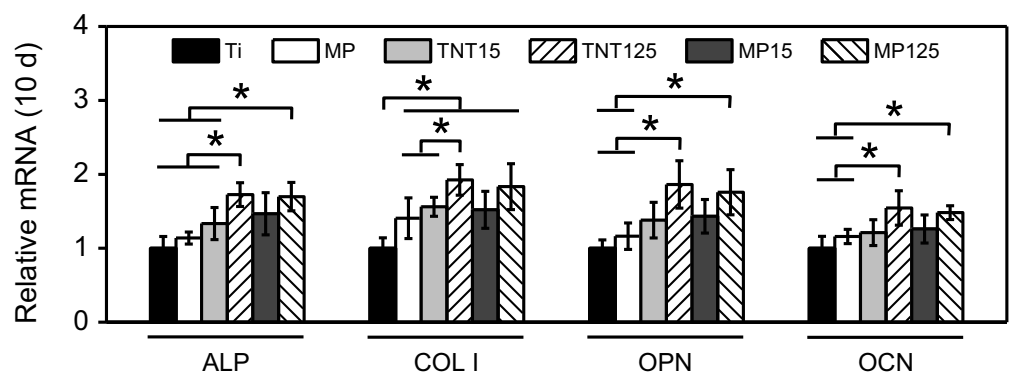

Figure 7 Expression of ALP, COL I , OPN and OCN genes in MC3T3-EI cells on different substrates at $3 \mathrm{~d}(\mathbf{A})$ and I $0 \mathrm{~d}(\mathbf{B})$. Error bars represent mean \pm SD for $n=6,{ }^{*} p<0.05$. 
Zhejiang Provincial Natural Science Foundation (LY17H140007), Zhejiang Provincial Science and Technology Project for Public Welfare (2015C33139) and China Postdoctoral Science Foundation funded project (2018T110946).

\section{Disclosure}

The authors report no conflicts of interest in this work.

\section{References}

1. Han C, Li Y, Wang Q, et al. Continuous functionally graded porous titanium scaffolds manufactured by selective laser melting for bone implants. J Mech Behav Biomed Mater. 2018;80:119-127. doi:10.1016/j.jmbbm.2018.01.013

2. Bandyopadhyay A, Shivaram A, Tarafder S, Sahasrabudhe H, Banerjee D, Bose S. In vivo response of laser processed porous titanium implants for load-bearing implants. Ann Biomed Eng. 2017;45(1):249-260. doi:10.1007/s10439-016-1673-8

3. Wang C, Wang S, Yang Y, et al. Bioinspired, biocompatible and peptide-decorated silk fibroin coatings for enhanced osteogenesis of bioinert implant. J Biomater Sci Polym Ed. 2018;29(13):1595-1611. doi:10.1080/09205063.2018.1477316

4. Huang Q, Liu X, Zhang R, et al. The development of Cu-incorporated micro/nano-topographical bio-ceramic coatings for enhanced osteoblast response. Appl Surf Sci. 2019;465:575-583. doi:10.1016/ j.apsusc.2018.09.208

5. Džunuzović ES, Džunuzović JV, Marinković AD, MarinovićCincović MT, Jeremić KB, Nedeljković JM. Influence of surface modified $\mathrm{TiO}_{2}$ nanoparticles by gallates on the properties of PMMA/TiO 2 nanocomposites. Eur Polym J. 2012;48(8):1385-1393. doi:10.1016/j.eurpolymj.2012.05.017

6. Erakovic S, Jankovic A, Tsui GC, Tang CY, Miskovic-Stankovic V, Stevanovic T. Novel bioactive antimicrobial lignin containing coatings on titanium obtained by electrophoretic deposition. Int J Mol Sci. 2014;15(7):12294-12322. doi:10.3390/ijms150712294

7. Wang J, Qian S, Liu X, et al. M2 macrophages contribute to osteogenesis and angiogenesis on nanotubular $\mathrm{TiO}_{2}$ surfaces. $J$ Mater Chem B. 2017;5:3364-3376. doi:10.1039/C6TB03364D

8. Cazzola M, Ferraris S, Boschetto F, et al. Green tea polyphenols coupled with a bioactive titanium alloy surface: in vitro characterization of osteoinductive behavior through a KUSA A1 cell study. Int $J$ Mol Sci. 2018;19(8):2255. doi:10.3390/ijms19082255

9. Gurzawska K, Svava R, Yihua Y, et al. Osteoblastic response to pectin nanocoating on titanium surfaces. Mater Sci Eng C Mater Biol Appl. 2014;43:117-125. doi:10.1016/j.msec.2014.06.028

10. Ferraris S, Spriano S, Bianchi CL, Cassinelli C, Vernè E. Surface modification of Ti-6Al-4 V alloy for biomineralization and specific biological response: part II, alkaline phosphatase grafting. J Mater $\mathrm{Sci}$ Mater Med. 2011;22(8):1835-1842. doi:10.1007/s10856-011-4365-9

11. Sileika TS, Barrett DG, Zhang R, Lau KH, Messersmith PB. Colorless multifunctional coatings inspired by polyphenols found in tea, chocolate, and wine. Angew Chem Int Ed Engl. 2013;52 (41):10766-10770. doi:10.1002/anie.201304922

12. Liu S, Li B, Liang C, Wang H, Qiao Z. Formation mechanism and adhesive strength of a hydroxyapatite $/ \mathrm{TiO}_{2}$ composite coating on a titanium surface prepared by micro-arc oxidation. Appl Surf Sci. 2016;362:109-114. doi:10.1016/j.apsusc.2015.11.086

13. Wu $\mathrm{C}$, Chen $\mathrm{Z}, \mathrm{Wu} \mathrm{Q}$, et al. Clinoenstatite coatings have high bonding strength, bioactive ion release, and osteoimmunomodulatory effects that enhance in vivo osseointegration. Biomaterials. 2015;71:35-47. doi:10.1016/j.biomaterials.2015.08.027
14. Bose S, Banerjee D, Shivaram A, Tarafder S, Bandyopadhyay A. Calcium phosphate coated $3 \mathrm{D}$ printed porous titanium with nanoscale surface modification for orthopedic and dental applications. Mater Design. 2018;151:102-112. doi:10.1016/j. matdes.2018.04.049

15. Nimb L, Gotfredsen K, Steen Jensen J. Mechanical failure of hydroxyapatite-coated titanium and cobalt-chromium-molybdenum alloy implants. An animal study. Acta Orthop Belg. 1993;59(4):333-338.

16. Cordova LA, Stresing V, Gobin B, et al. Orthopaedic implant failure: aseptic implant loosening-the contribution and future challenges of mouse models in translational research. Clin Sci. 2014;127(5):277293. doi:10.1042/CS20130338

17. Yu Y, Shen X, Luo Z, et al. Osteogenesis potential of different titania nanotubes in oxidative stress microenvironment. Biomaterials. 2018;167:44-57. doi:10.1016/j.biomaterials.2018.03.024

18. Pawlik A, Jarosz M, Syrek K, Sulka GD. Co-delivery of ibuprofen and gentamicin from nanoporous anodic titanium dioxide layers. Colloids Surf B Biointerfaces. 2017;152:95-102. doi:10.1016/j. colsurfb.2017.01.011

19. $\mathrm{Li} \mathrm{M}$, Yang Y. Nanoscale $\mathrm{TiO}_{2}$ nanotubes as a basis for governing cell behaviors and application challenges. Int $J$ Nanomedicine. 2017;12:575-576. doi:10.2147/IJN.S128749

20. Park J, Bauer S, Schmuki P, von der Mark K. Narrow window in nanoscale dependent activation of endothelial cell growth and differentiation on $\mathrm{TiO}_{2}$ nanotube surfaces. Nano Lett. 2009;9(9):31573164. doi: $10.1021 / \mathrm{n} 19013502$

21. Oh S, Brammer KS, Li YS, et al. Stem cell fate dictated solely by altered nanotube dimension. Proc Natl Acad Sci U S A. 2009;106 (7):2130-2135. doi:10.1073/pnas.0813200106

22. Yu D, Zhu X, Xu Z, et al. Facile method to enhance the adhesion of $\mathrm{TiO}_{2}$ nanotube arrays to Ti substrate. ACS Appl Mater Interfaces. 2014;6(11):8001-8005. doi:10.1021/am5015716

23. Xiong J, Wang X, Li Y, Hodgson PD. Interfacial chemistry and adhesion between titanium dioxide nanotube layers and titanium substrates. J Phys Chem C. 2011;115(11):4768-4772. doi:10.1021/ jp111651d

24. Sun M, Yu D, Lu L, Ma W, Song Y, Zhu X. Effective approach to strengthening $\mathrm{TiO}_{2}$ nanotube arrays by using double or triple reinforcements. Appl Surf Sci. 2015;346:172-176. doi:10.1016/j. apsusc.2015.04.004

25. Kim TJ, Jung YH, Zhang H, Kim K, Lee J, Ma Z. Photolithography-based nanopatterning using re-entrant photoresist profile. ACS Appl Mater Interfaces. 2018;10(9):8117-8123. doi:10.1021/acsami.7b17628

26. Brevnov DA, Barela M, Piyasena ME, López GP, Atanassov PB. Patterning of nanoporous anodic aluminum oxide arrays by using solgel processing, photolithography, and plasma etching. Chem Mater. 2004;16(4):682-687. doi:10.1021/cm034553v

27. Chen Z, Li Y, Wang B, Wei B, Yang L. Enhanced photolithography with al film insertion for large-scale patterning of CVD grapheme. Opt Mater Express. 2018;8(8):2403-2414. doi:10.1364/OME.8.002403

28. Zhang R, Elkhooly TA, Huang Q, et al. Effects of the hierarchical macro/ mesoporous structure on the osteoblast-like cell response. J Biomed Mater Res A. 2018;106(7):1896-1902. doi:10.1002/jbm.a.36387

29. Liu J, Pathak JL, Hu X, et al. Sustained release of zoledronic acid from mesoporous $\mathrm{TiO}_{2}$-layered implant enhances implant osseointegration in osteoporotic condition. J Biomed Nanotechnol. 2018;14 (11):1965-1978. doi:10.1166/jbn.2018.2635

30. Yuan Z, Liu P, Liang $\mathrm{Y}$, et al. Investigation of osteogenic responses of $\mathrm{Fe}$-incorporated micro/nano-hierarchical structures on titanium surfaces. J Mater Chem B. 2018;6:1359-1372. doi:10.1039/C7TB03071A

31. Ren B, Wan Y, Wang G, Liu Z, Huang Y, Wang H. Morphologically modified surface with hierarchical micro-/nano-structures for enhanced bioactivity of titanium implants. J Mater Sci. 2018;53 (18):12679-12691. doi:10.1007/s10853-018-2554-3 
32. Gittens RA, McLachlan T, Olivares-Navarrete R, et al. The effects of combined micron-/submicron-scale surface roughness and nanoscale features on cell proliferation and differentiation. Biomaterials. 2011;32 (13):3395-3403. doi:10.1016/j.biomaterials.2011.01.029

33. Chen X, Cai K, Lai M, Li Z, Tang L. Mesenchymal stem cells differentiation on hierarchically micro/nano-structured titanium substrates. Adv Eng Mater. 2012;14(5):B216-B223. doi:10.1002/ adem.201180073

34. Gilpin AD, Oakley BR, Dillingham RG. Water contact angle as a quantitative measure of total polyethylene surface energy. $J$ Adhes Sci Technol. 2015;29(9):890-895. doi:10.1080/01694243.2015.1 006906

35. Goebel MO, Bachmann J, Woche SK, Fischer WR, Horton R. Water potential and aggregate size effects on contact angle and surface energy. Soil Sci Soc Am J. 2004;68(2):383-393. doi:10.2136/sssaj2004.3830

36. Pugachevskii MA. Ultraviolet absorption spectrum of laser-ablated titanium dioxide nanoparticles. Tech Phys Lett. 2013;39(1):36-38. doi:10.1134/S1063785013010239

37. Cao S, Huang W, Wu L, Tian M, Song Y. On the interfacial adhesion between $\mathrm{TiO}_{2}$ nanotube array layer and Ti substrate. Langmuir. 2018;34(46):13888-13896. doi:10.1021/acs.langmuir.8b03408

38. Sridharan R, Cameron AR, Kelly DJ, Kearney CJ, O'Brien FJ. Biomaterial based modulation of macrophage polarization: a review and suggested design principles. Mater Today. 2015;18(6):313-325. doi:10.1016/j.mattod.2015.01.019

39. Martínez-Ibáñez M, Murthy NS, Mao Y, et al. Enhancement of plasma protein adsorption and osteogenesis of hMScs by functionalized siloxane coatings for titanium implants. J Biomed Mater Res B Appl Biomater. 2018;106(3):1138-1147. doi:10.1002/jbm.b.33889

40. Firkowska-Boden I, Zhang X, Jandt KD. Controlling protein adsorption through nanostructured polymeric surfaces. Adv Healthc Mater. 2018;7(1):1700995. doi:10.1002/adhm.201700995
41. Yang W, Xi X, Shen X, Liu P, Hu Y, Cai K. Titania nanotubes dimensions-dependent protein adsorption and its effect on the growth of osteoblasts. J Biomed Mater Res A. 2014;102(10):3598-3608. doi:10.1002/jbm.a.35021

42. Gongadze E, Kabaso D, Bauer S, Park J, Schmuki P, Iglič A. Adhesion of osteoblasts to a vertically aligned $\mathrm{TiO}_{2}$ nanotube surface. Mini Rev Med Chem. 2013;13(2):194-200.

43. Brammer KS, Oh S, Cobb CJ, Bjursten LM, van der Heyde H, Jin S. Improved bone-forming functionality on diameter-controlled $\mathrm{TiO}_{2}$ nanotube surface. Acta Biomater. 2009;5(8):3215-3223. doi:10.1016/j.actbio.2009.05.008

44. Siller AF, Whyte MP. Alkaline phosphatase: discovery and naming of our favorite enzyme. J Bone Miner Res. 2018;33(2):362-364. doi:10.1002/jbmr.3225

45. Jo YK, Choi BH, Kim CS, Cha HJ. Diatom-inspired silica nanostructure coatings with controllable microroughness using an engineered mussel protein glue to accelerate bone growth on titaniumbased implants. Adv Mater. 2017;29(46):1704906. doi:10.1002/ adma.201700681

46. He Y, Mu C, Shen X, et al. Peptide LL-37 coating on micro-structured titanium implants to facilitate bone formation in vivo via mesenchymal stem cell recruitment. Acta Biomater. 2018;80:412424. doi:10.1016/j.actbio.2018.09.036

47. Wennberg C, Hessle L, Lundberg P, et al. Functional characterization of osteoblasts and osteoclasts from alkaline phosphatase knockout mice. J Bone Miner Res. 2000;15(10):1879-1888. doi:10.1359/ jbmr.2000.15.10.1879

48. Orimo H, Shimada T. The role of tissue-nonspecific alkaline phosphatase in the phosphate-induced activation of alkaline phosphatase and mineralization in SaOS-2 human osteoblast-like cells. Mol Cell Biochem. 2008;315(1-2):51-60. doi:10.1007/s11010-008-9788-3
International Journal of Nanomedicine

\section{Publish your work in this journal}

The International Journal of Nanomedicine is an international, peerreviewed journal focusing on the application of nanotechnology in diagnostics, therapeutics, and drug delivery systems throughout the biomedical field. This journal is indexed on PubMed Central, MedLine, CAS, SciSearch ${ }^{\mathbb{B}}$, Current Contents ${ }^{\mathbb{R}} /$ Clinical Medicine,
Journal Citation Reports/Science Edition, EMBase, Scopus and the Elsevier Bibliographic databases. The manuscript management system is completely online and includes a very quick and fair peer-review system, which is all easy to use. Visit http://www.dovepress.com/ testimonials.php to read real quotes from published authors. 